\title{
Power to gas-oxyfuel boiler hybrid systems
}

\author{
Manuel BAILERA $^{\mathrm{a}}$, Pilar LISBONA ${ }^{\mathrm{a}}$, Luis M. ROMEO ${ }^{\mathrm{a}}$ \\ ${ }^{a}$ Research Centre for Energy Resources and Consumption (CIRCE) - Universidad de Zaragoza, \\ CIRCE Building - Campus Río Ebro, Mariano Esquillor Gómez, 15, 50018 \\ Zaragoza, Spain
}

\begin{abstract}
One of the main future energy challenges is the management of electrical supply and demand, mainly motivated by the increase of share renewable energy in electricity mix. Thus, energy storage represents a crucial line of research and innovative solutions are currently being proposed. Power to Gas is a technology which stores excess of electrical energy in form of synthetic natural gas through the methanation of hydrogen produced by electrolysis. Methanation requires a source of $\mathrm{CO}_{2}$ which could be provided from the flue gas of an oxyfuel boiler. A further advantage of this hybridization comes from the supply of the oxygen generated by electrolysis to the oxyfuel combustion. In this study the concept is simulated using Aspen Plus ${ }^{\circledR}$ software and the performance of the combined system is analysed through the definition of a size ratio, $\xi_{o x y}$, that relates the flow of renewable hydrogen produced in electrolyser and the thermal output of the boiler. This variable has allowed defining different ranges of operation for a PtGoxycombustion hybridized plant. Thus, for $\xi_{o x y}$ of 1.33 , the air separation unit required as an auxiliary element for the oxyfuel boiler becomes unnecessary while if this ratio is increased up to 2.29 , flue gas is completely consumed in the methanation plant and converted to synthetic natural gas.
\end{abstract}




\section{Keywords}

Power-to-Gas, Oxyfuel Combustion, Methanation

\section{Introduction}

The constant increase of the renewable energy share in energy markets brings about the appearance of mismatches between supply and electrical demand which affect to security and stability of the grid [1]. The accommodation of energy production with consumption has become a critical challenge for future society that is being tackled by developing innovative energy storage solutions [2].

The low energy density and limited storage potential of pumped hydroelectric storage, compressed air energy storage, flywheels and batteries, make Power to Gas technology one promising option to overcome these limitations [3]. PtG converts electricity in synthetic natural gas that may substitute fossil fuels or be injected into the natural gas network which would be used as storage infrastructure [4]. In this way, electric and gas networks would be connected as a unique energy system increasing the flexibility of the energy supply [5].

In a generic PtG system, the conversion of electricity is strictly carried out by an electrolyser which produces hydrogen. The consumption of this gas through Sabatier chemical reaction (Eq. 1) produces methane and the synthetic natural gas is obtained.

$\begin{array}{ll}\text { Abbreviations } & \\ \text { ASU } & \text { Air separation unit } \\ \text { FG } & \text { Flue gas } \\ \text { LHV } & \text { Lower heating value } \\ \text { M1 } & \text { Methanator 1 } \\ \text { M2 } & \text { Methanator 2 } \\ \text { M3 } & \text { Methanator 3 } \\ \text { PtG } & \text { Power to Gas } \\ \text { SNG } & \text { Synthetic natural gas }\end{array}$


The global process is carried out through two consecutive reactions: inverse water-gas shift reaction (Eq. 2) and CO methanation (Eq. 3) [6].

$$
\begin{array}{lc}
\mathrm{CO}_{2}+4 \mathrm{H}_{2} \leftrightarrow \mathrm{CH}_{4}+2 \mathrm{H}_{2} \mathrm{O} & \Delta \mathrm{H}_{298 \mathrm{~K}}=-164.9 \mathrm{~kJ} / \mathrm{mol} \\
\mathrm{CO}_{2}+\mathrm{H}_{2} \leftrightarrow \mathrm{CO}+\mathrm{H}_{2} \mathrm{O} & \Delta \mathrm{H}_{298 \mathrm{~K}}=+41.5 \mathrm{~kJ} / \mathrm{mol} \\
\mathrm{CO}+3 \mathrm{H}_{2} \leftrightarrow \mathrm{CH}_{4}+\mathrm{H}_{2} \mathrm{O} & \Delta \mathrm{H}_{298 \mathrm{~K}}=-206.4 \mathrm{~kJ} / \mathrm{mol}
\end{array}
$$

Equation (2) is an endothermic reaction which requires the presence of a catalyst to take place at low temperatures. It promotes conversion to methane in Equation (3).

Additionally, when the power input to the electrolyser is supplied by renewable energy sources, the obtained SNG will be neutral in $\mathrm{CO}_{2}$ emissions. The same amount of $\mathrm{CO}_{2}$ that will be emitted through SNG combustion is required and consumed during its synthesis process.

Different PtG concepts such as hybridization with air separation plants, biogas plants, biomass gasification, sewage plants, fossil power plants or industrial processes have been proposed to obtain the source of carbon dioxide [5]. Two main issues in the PtG systems are the utilization of the residual oxygen produced by electrolysis and the consumption of energy to attain a concentrated stream of $\mathrm{CO}_{2}$.

Some of the major projects in the world related to methanation (MeGa-stoRE 4.7 MW [7], Erdgas Schwaben 1.0 MW [8], and P2G-BioCat 1.0 MW [9]) upgrade biogas to obtain SNG without previous $\mathrm{CO}_{2}$ separation, but oxygen from electrolyser do not have a final use. Biomass gasification and sewage plants would solve both issues since oxygen may be used as gasification agent or for the activation of sludge [5]. However, syngas from gasification achieves hydrogen content above $60 \%$ and further hydrogen addition is barely needed limiting energy storage potential [7]. Additionally, sewage 
plants produce poor syngas whose conversion to SNG is relatively expensive. Thus, it is currently preferred to burn this gas in engines for self-consumption [10].

Hence, a suitable option for taking advantage of produced oxygen would be the hybridation of PtG with oxyfuel combustion. In an oxyfuel combustion, a mixture of oxygen and recycled flue gas acts as comburent [11]. Thus, oxygen from electrolyser would reduce the electrical consumption of the required air separation unit, and $\mathrm{CO}_{2}$ would be taken from the boiler flue gas without extra energy penalty in its separation.

The objective of the study is to determine the global efficiency that would have this hybrid system, the flows of generated $\mathrm{SNG}$ and stored $\mathrm{CO}_{2}$ and other potential variations in the efficiencies of specific elements of the installation as a function of electric power consumption in electrolyser. In addition, the operating ranges for an oxyfuel combustion plant hybridized with Power to Gas technology will be determined highlighting the most convenient size ratios between oxyfuel and PtG plants.

The model and simulation of the proposed concept has been performed under steady state of operation, considering that it will work at full load most part of the year. In Spain, France and Germany, energy loss due to curtailment of wind-generated energy remained under $1 \%$ of total wind production during 2010, 2011 and 2012 [11]. Thus, operation of $\mathrm{PtG}$ must not be limited to operate with the surplus of electricity from renewable sources. It should be understood as a method for continuous production of SNG and a sink of $\mathrm{CO}_{2}$ emissions although the proposed concept may also be applied for energy storage. 


\section{Hybrid system description and calculation methods}

In this section, a thorough description of the hybrid PtG-Oxyfuel boiler system is presented together with the most important interactions between technologies. The input data to the Aspen Plus ${ }^{\circledR}$ simulation engine as well as the chosen calculation methods are also described. Buchholz et al. investigated the combination of a PtG plant and conventional lignite fired power plant [12]. However, no previous analyses of the combined system PtG and oxyfuel boiler with thermal purposes are found in literature. Thus, the efficiencies of the single elements and the hybrid concept are still to be defined.

\subsection{Description of the hybrid concept}

Figure 1 illustrates the schematic diagram of the hybrid concept. In order to allow for continuous operation, the system is designed to be fed with a constant power input. A source of renewable energy supplies power to electrolysers which store this renewable energy as hydrogen also producing oxygen as a by-product. This amount of oxygen may partially or completely cover the comburent demand in the oxyfuel boiler, increasing the efficiency of this process since the ASU power consumption is reduced. Additionally, methanation takes place between the flue gas from the oxyfuel thermal plant (basically $\mathrm{CO}_{2}$ and $\mathrm{O}_{2}$ ) and the hydrogen from electrolysis to produce synthetic natural gas. 


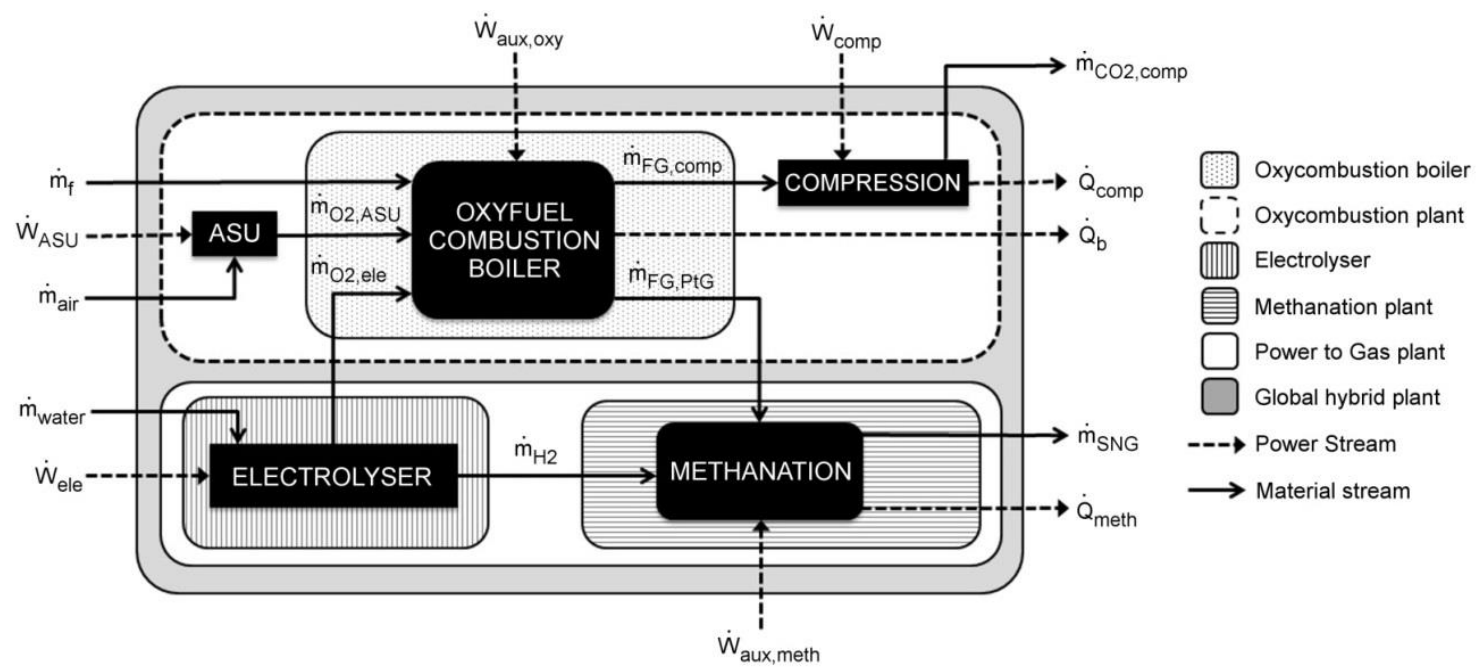

Figure 1. Scheme of the hybrid power system.

Besides the heat recovered from the oxyfuel boiler, a significant amount of thermal energy is released from the exothermic reaction in methanators and the intercooling stages in compression trains. This extra available heat could be integrated in external thermal processes or in the hybrid concept itself.

\subsection{Hybrid system modelling with Aspen Plus ${ }^{\circledR}$}

The proposed scheme for the hybridization between oxycombustion and PtG technologies has been modelled with Aspen Plus ${ }^{\circledR}$ under industrial conditions for steady state operation and chemical equilibrium. In the following, information on the model of each significant element in the system is presented.

Coal is selected as input material for the oxyfuel combustion process since it represents the most extended fossil fuel for thermal energy supply in industry [13]. The ultimate analysis of coal is presented in Table 1.

Table 1. Ultimate analysis of coal for oxycombustion [\% w.b.]. 


\begin{tabular}{|r|r|r|r|r|r|r|r|}
\hline $\mathrm{C}$ & $\mathrm{H}$ & $\mathrm{O}$ & $\mathrm{N}$ & $\mathrm{S}$ & $\mathrm{M}$ & $\mathrm{Z}$ & $\mathrm{LHV}[\mathrm{MJ} / \mathrm{kg}]$ \\
\hline 66.1 & 3.6 & 7.1 & 1.6 & 0.6 & 8.6 & 12.4 & 25.4 \\
\hline
\end{tabular}

\section{Oxyfuel combustion plant}

Figure 2 illustrates a scheme of the model developed in Aspen Plus ${ }^{\circledR}$ for the oxyfuel plant. Fuel and comburent are introduced into the boiler to reach chemical equilibrium by minimizing Gibbs free energy.

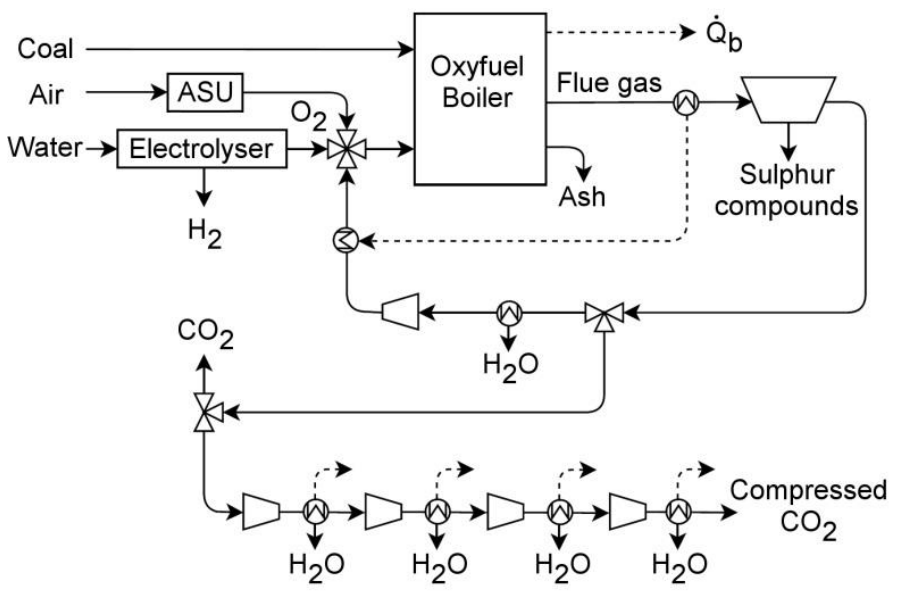

Figure 2. Oxyfuel combustion plant model.

Flue gas passes through the heat exchangers where steam is produced reducing its temperature down to $270{ }^{\circ} \mathrm{C}$. This energy corresponds to the useful output thermal power of the oxyfuel boiler, $\dot{Q}_{b}$. Then, flue gas is cooled down to $190{ }^{\circ} \mathrm{C}$ to preheat the comburent up to around $150{ }^{\circ} \mathrm{C}$. Once ashes and sulphur compounds are removed, $80 \%$ of gas is recirculated to the boiler and the remaining is directed to $\mathrm{CO}_{2}$ compression stage or to methanation process. Large content of water in the recirculated flue gas must be avoided. Thus, a condensation stage is located prior comburent mixing for oxyfuel applications. The comburent is mainly composed by oxygen from ASU, oxygen from 
electrolyser and preheated recirculated flue gas. The air separation unit module provides pure oxygen at $15{ }^{\circ} \mathrm{C}$ and 1 bar. According to literature, its electrical consumption is assumed to be $190 \mathrm{kWh} / \mathrm{tO}_{2}$ [14]. The oxygen excess in the boiler is set as $15 \%$ and it accounts for the oxygen from ASU and electrolyser.

\section{$\mathrm{CO}_{2}$ compression stage}

The stream of concentrated $\mathrm{CO}_{2}$ from oxyfuel combustion which is not reused in methanation stage is directed to the compression train to be transported and stored. The train consists of three compressors with pressure ratios of 3.5 and another one with pressure ratio of 3.0, which reaches a final pressure of 111.4 bar. Additionally, there exist four intermediate condensers to remove water, leading to a final $\mathrm{CO}_{2}$ purity of $94.2 \%$. These intercoolers reduce the temperature of $\mathrm{CO}_{2}$ stream down to $40{ }^{\circ} \mathrm{C}$.

\section{Electrolyser}

The power from a renewable source is modelled as an energy input to the electrolyser module. By varying this input, the amount of produced hydrogen will be modified, and consequently the percentage of flue gas directed to the PtG process, the flow of generated SNG, and the global hybrid system operation efficiency.

Alkaline electrolyser has been modelled by programming a user-defined subroutine in Aspen Plus ${ }^{\circledR}$. The inlet electric power and the inlet water stream are the initial variables for the external calculations. This block splits water in two mass flows of pure oxygen and a mixture of hydrogen with unreacted water. Based on literature, the water conversion is assumed to be $99.9 \%$ with an electrical consumption range from 4.3 to 4.9 $\mathrm{kWh} / \mathrm{Nm}^{3} \mathrm{H}_{2}$ and an outlet temperature of $80{ }^{\circ} \mathrm{C}[15][16]$. These operation conditions leads to an efficiency range of the electrolyser unit, $\eta_{L H V}=61.2-69.7 \%$. 


\section{Methanation plant}

The proposed scheme of methanation is based on TREMP ${ }^{\mathrm{TM}}$ process of Haldor Topsøe, which manages three adiabatic reactors at 30 bar with one recirculation on the first methanator [17]. It makes use of high temperature catalysts to reduce the cooling requirements in the reactors and diminish the recirculated flow while also the extrathermal energy production can be recovered as high pressure steam [18].

The main target of the methanation plant is to achieve methane molar fractions above $95 \%$ in the SNG to inject it into the natural gas network. This threshold concentration corresponds to Spanish legislation for natural gas composition [19]. The proposed configuration, shown in Figure 3, consists of three adiabatic reactors and an intermediate condensation stage, which operate at 30 bar and temperatures between 250 ${ }^{\circ} \mathrm{C}$ and $550{ }^{\circ} \mathrm{C}$. Reactor blocks (M1, M2 and M3) calculate the composition and temperature of outlet gas streams, at equilibrium state, minimizing Gibbs free energy in an adiabatic process.

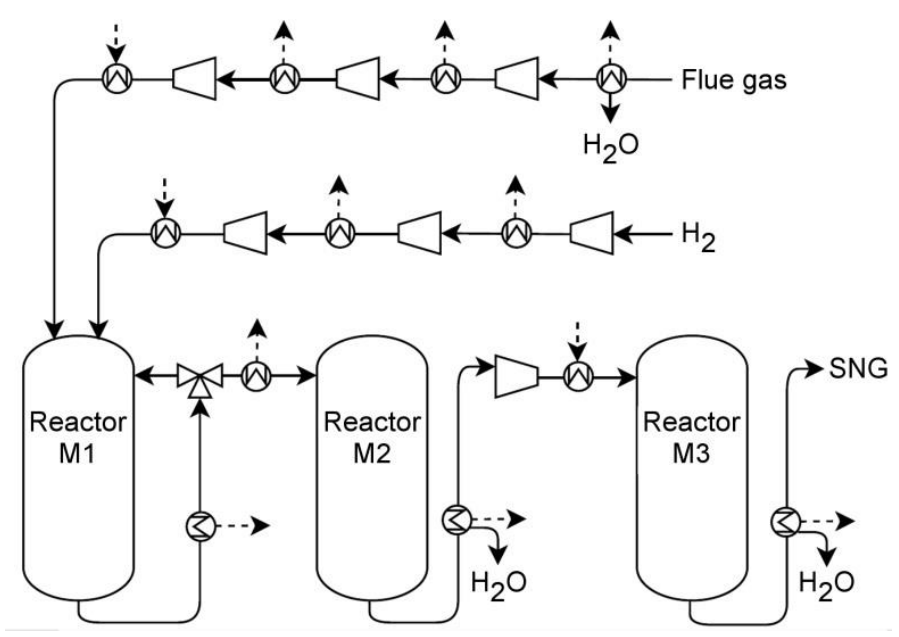

Figure 3. Methanation plant model. 
The flue gas flow from oxyfuel combustion directed to methanation process is determined by electrical power consumption in electrolyser, and $\mathrm{CO}_{2}$ and $\mathrm{O}_{2}$ concentration in flue gas. Since the presence of oxygen in flue gas would poison the catalysts [20], it must be consumed through a controlled combustion with part of the generated hydrogen. A constant $\mathrm{H}_{2}: \mathrm{CO}_{2}$ molar ratio of 4 has been set at the inlet of the first reactor (Equation 1). These two conditions are used to derive Equation 4 and calculate the percentage of flue gas directed to methanation, $\phi_{F G M}$. The last parameter, $\dot{n}_{\mathrm{CO}_{2}, \text { Loss }}$, corresponds to the $\mathrm{CO}_{2}$ lost with water in the condensation stage prior the compression train, which is needed since a large presence of steam inhibits methanation reaction.

$$
\phi_{F G M}=100\left[\left(y_{\mathrm{CO}_{2}, \mathrm{FG}}+\frac{1}{2} y_{\mathrm{O}_{2}, \mathrm{FG}}\right)^{-1} \frac{\left(\dot{n}_{\mathrm{H}_{2}} / 4+\dot{n}_{\mathrm{CO}_{2}, \mathrm{LOSS}}\right)}{\dot{n}_{\mathrm{FG}}}\right]
$$

Both, hydrogen and flue gas are passed through two compression trains with intermediate heat recoveries reaching the operation pressure of the process (30 bar) prior the first methanator. The intercooling temperature is limited to $120{ }^{\circ} \mathrm{C}$ since a subsequent preheating up to $300{ }^{\circ} \mathrm{C}$ is required [21].

The syngas is cooled down to $300{ }^{\circ} \mathrm{C}$ after Reactor 1 , M1. Most of the SNG outlet stream is recirculated to maintain the temperature near $550{ }^{\circ} \mathrm{C}$, since the loss of active surface area by atom migration sintering mechanism becomes important above $600{ }^{\circ} \mathrm{C}$ [22].

Then, the temperature of the stream is reduced to $250^{\circ} \mathrm{C}$ before entering Reactor $2, \mathrm{M} 2$, promoting the upgrade of the syngas. Lower inlet temperatures are typical in second and following methanators of commercial SNG processes like TREMP ${ }^{\circledR}$ [23]. 
At the exit of Reactor 2 syngas stream is cooled down and steam content is partially condensed to avoid the inhibition of the reaction of methanation. However, it must be taken into account that an excessively low steam molar fraction could generate solid carbon depositions during methanation [6]. In addition, since steam content has been largely reduced, the pressure $\left(30\right.$ bar) and temperature $\left(250{ }^{\circ} \mathrm{C}\right)$ must be recovered prior the third methanation step.

The third reactor, M3, also operates without recirculation since sufficiently high pressures favours methane formation. The outlet stream is cooled down to $40{ }^{\circ} \mathrm{C}$ to condense steam and reach a purity of methane over $95 \%$.

\subsection{Definition of partial and global efficiencies}

The partial energy efficiencies of the independent elements and the efficiency of the subsystems are defined through the following equations: Eq. 5 corresponds to the boiler efficiency; Eq. 6 defines the efficiency of the oxycombustion subsystem where compression train is included; Eq. 7 presents the efficiency of the electrolyzer; methanation plant efficiency is calculated through Eq. 8 and, finally, Eq. 9 expresses the efficiency of the PtG subsystem. These are the ratios between useful energy output and energy input for the different control volumes of the systems established in Figure 1.

$$
\begin{gathered}
\eta_{b}=\frac{\dot{Q}_{b}}{L H V_{f} \dot{m}_{f}+\dot{W}_{a u x, o x y}} \\
\eta_{o x y}=\frac{\dot{Q}_{b}}{L H V_{f} \dot{m}_{f}+\dot{W}_{a u x, o x y}+\dot{W}_{c o m p}+\dot{W}_{A S U}} \\
\eta_{e l e}=\frac{L H V_{H 2} \dot{m}_{H 2}}{\dot{W}_{e l e}} \\
\eta_{\text {meth }}=\frac{L H V_{S N G} \dot{m}_{S N G}}{L H V_{H 2} \dot{m}_{H 2}+\dot{W}_{a u x, m e t h}}
\end{gathered}
$$




$$
\eta_{P t G}=\frac{L H V_{S N G} \dot{m}_{S N G}}{\dot{W}_{\text {ele }}+\dot{W}_{\text {aux }, \text { meth }}}
$$

Auxiliary work of the methanation plant includes the consumptions of flue gas and $\mathrm{H}_{2}$ compression trains, and preheating and cooling systems.

The global efficiency of the hybrid plant is given by Equation 10. Depending on the operation strategy of the system some of the parameters in the equations may be neglected.

$$
\eta_{P t G+o x y}=\frac{\dot{Q}_{b}+L H V_{S N G} \dot{m}_{S N G}}{L H V_{f} \dot{m}_{f}+\dot{W}_{a u x, o x y}+\dot{W}_{c o m p}+\dot{W}_{A S U}+\dot{W}_{e l e}+\dot{W}_{a u x, m e t h}}
$$

\section{Results and discussion}

The results obtained in the performed analysis are divided into four main points that are separately discussed: (i) determination of the Power to Gas plant operation point, (ii) study of the operation ranges of the hybrid system, (iii) analysis of energy efficiencies and (iv) quantification of produced $\mathrm{SNG}$ and avoided $\mathrm{CO}_{2}$.

\subsection{Operation point of the Power to Gas plant}

Four parameters control the process in the PtG plant; two of them, the initial $\mathrm{H}_{2}: \mathrm{CO}_{2}$ molar ratio and the inlet temperature to reactors are kept constant. The molar ratio is fixed to preserve the stoichiometry of reaction (Eq. 1) and the optimal operation temperature for the commercial catalysts [24]. The two remaining variables are the amount of steam condensed in the intermediate condensation stage, and the recirculation in Reactor 1, M1. Recirculation controls operation temperature inside the reactor, producing changes in the equilibrium constants and outlet concentrations; the lower temperature, the more enhanced methanation [6]. 
Reducing steam content also displaces equilibrium towards methane production. However, there exists a lower limit for steam concentration since solid carbon deposition may occur in the reactors inhibiting the catalysts [20] [6]. This limitation points out the existence of a threshold for minimum condensation temperature in the intermediate stage which determines the amount of removed water. The deposition of solid carbon per kilogram of hydrogen produced in the electrolyser is calculated in Aspen Plus ${ }^{\circledR}$ as a function of the condenser temperature and the recirculation in Reactor 1 and illustrated in Figure 4. The temperature must be set over $125.5^{\circ} \mathrm{C}$ to ensure the avoidance of solid carbon deposition for $90 \%$ of M1 recirculation; it was kept in 130.0 ${ }^{\circ} \mathrm{C}$. The specific deposition of solid carbon per unit of $\mathrm{kW}$ consumed in electrolyser remains constant for different sizes of electrolyser, since the deposited amount is proportional to the syngas flow and, thus, to the electrolyser power. In Figure 4, carbon deposition is normalized with respect to the amount of generated hydrogen to avoid the influence of electrolyser efficiency.

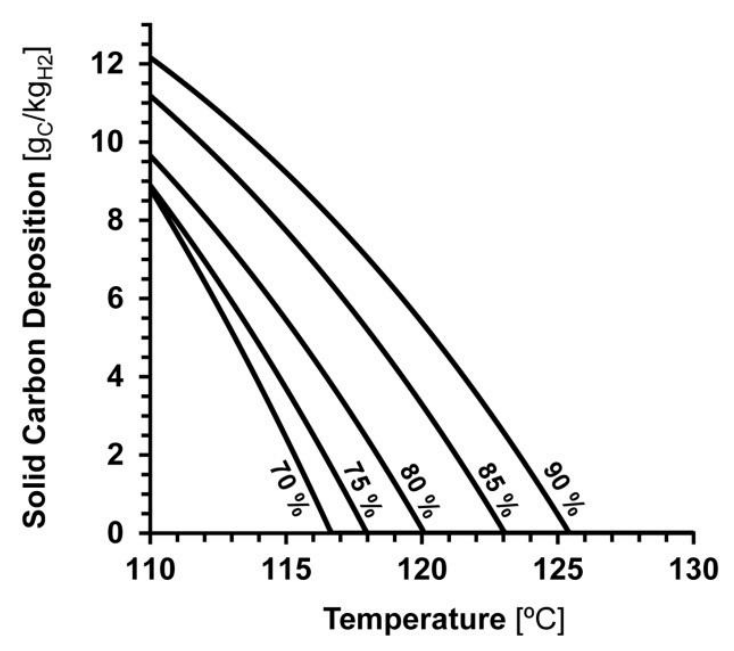

Figure 4. Specific deposition of solid carbon vs. condensation temperature and M1 recirculation. 
The recirculation in Reactor 1 is fixed to achieve a minimum $95 \%$ of purity of methane in the final SNG [19]. It should be noted that methane concentration will depend on the composition of oxyfuel boiler flue gas and, therefore, on the type of coal fed to the boiler. In this case, a minimum recirculation of $79.75 \%$ is needed to achieve methane molar fractions above $95 \%$ (see figure 5). The chosen point of operation recirculates $80.5 \%$, thus, small variations on recirculated stream will not reduce methane content below $95 \%$.

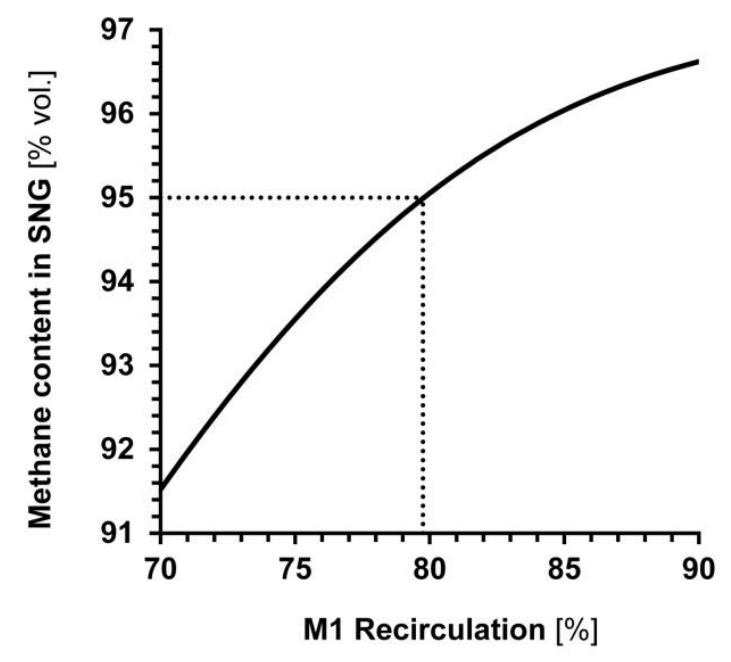

Figure 5. Methane molar fraction vs. recirculation

Under these conditions of operation for the Power to Gas subsystem, the molar composition of the obtained SNG is $95.17 \%$ methane, $2.48 \%$ hydrogen, $1.01 \%$ carbon dioxide, $1.00 \%$ nitrogen and $0.32 \%$ water.

\subsection{Operation ranges of the hybrid system}

The hybridized plant is characterized by a high reutilization of by-products that modifies auxiliary works, available heats and required equipment. Hence, the operation of the entire system will vary depending on the relative amount of energy sent to the electrolyser. The best approach to analyse the performance of the system is to define the 
ratio between energy contained in the hydrogen produced by electrolysis and net thermal power produced in the oxyfuel boiler. The behaviour of the system keeps constant for a fixed ratio even if scale is modified. Scale effects in the hybrid system would mainly affect heat exchanger network and pressure drop; both may be neglected for the scope of this analysis. The ratio of the hybrid system may be expressed as shown in Equation 11.

$$
\xi_{o x y}=\frac{L H V_{H 2} \cdot \dot{m}_{H 2}}{\dot{Q}_{b}}\left[\frac{k W_{H 2}}{k W_{t h}}\right]
$$

The main benefit of the hybridization between PtG and oxyfuel combustion is to substitute completely or partially the ASU unit with oxygen by-produced in electrolysis. In Figure 6, the variation of the specific electric power consumption of ASU $\left(\dot{W}_{A S U} / \dot{Q}_{b}\right)$ versus $\xi_{o x y}$ is illustrated. The minimum required ratio between electrolyser and boiler outputs to avoid the ASU is denoted by $\xi_{A S U}$ and a value of 1.33 has been obtained through simulation. The consumption of flue gas at this operation point is $57.9 \%$, and in order to achieve a total utilization of the $\mathrm{CO}_{2}$ generated in the oxyfuel boiler, a ratio of 2.29 is necessary (denoted by $\xi_{\mathrm{CO} 2}$ ).

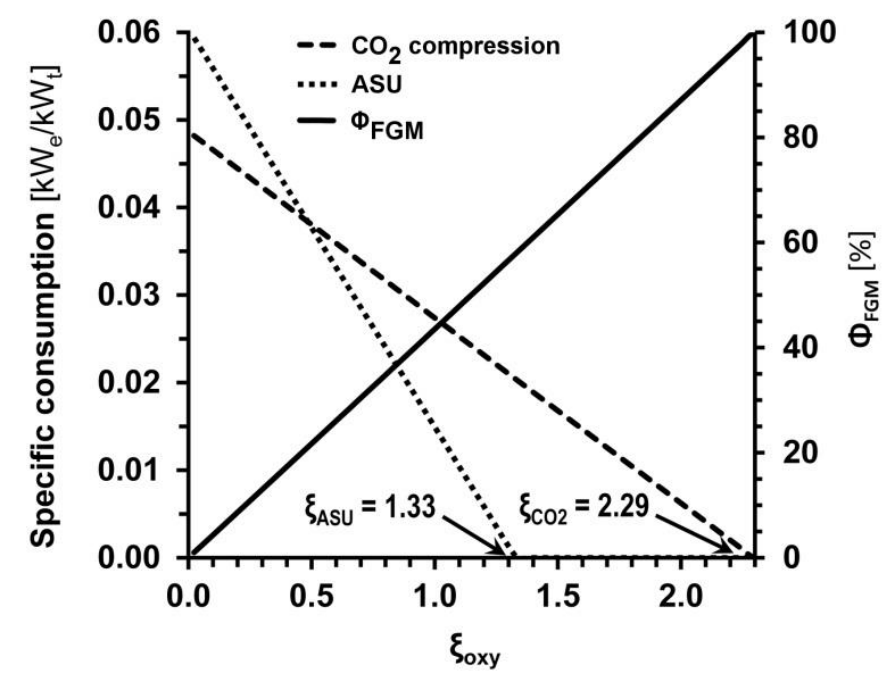


Figure 6. Specific consumptions and percentage of consumed flue gas vs. $\xi_{\text {oxy }}$

Depending on electrolyser efficiency $(61.2-69.7 \%$ [15][16]), the specific consumption of electrolysis lie on the range $1.91-2.17 \mathrm{~kW}_{\mathrm{e}} / \mathrm{kW}_{\text {th }}$ for operation point $\xi_{A S U}$, and between $3.29-3.74 \mathrm{~kW}_{\mathrm{e}} / \mathrm{kW}_{\text {th }}$ for $\xi_{\mathrm{CO} 2}$.

Auxiliary work on hybrid oxycombustion plant is mainly related to the recirculation of flue gas to the boiler, so it is independent of the electricity supplied to the Power to Gas subsystem, with a constant value of $2.710^{-3} \mathrm{~kW}_{\mathrm{e}} / \mathrm{kW}_{\mathrm{t}}$. Methanation auxiliary work, $\dot{W}_{\text {aux,meth }}$, linearly increases with $\xi_{\text {oxy }}$ from zero to its maximum value at $\xi_{\mathrm{CO} 2}, 0.205$ $\mathrm{kW}_{\mathrm{e}} / \mathrm{kW}_{\mathrm{t}}$, and it includes compression train $(89.8 \%)$, preheating $(6.0 \%)$ and cooling requirements $(4.2 \%)$.

\subsection{Analysis of partial and global efficiencies}

The efficiencies of the different elements in the hybrid system are calculated from the previously defined equations (Eq. 5 -9) and presented in Table 2 together with other relevant ratios for different representative values of $\xi_{o x y}$.

Table 2. Main parameters and efficiencies of the hybrid system.

\begin{tabular}{|c|c|c|c|c|c|c|c|}
\hline$\xi_{\text {oxy }}$ & $\Phi_{F G M}$ & $\dot{W}_{A S U} / \dot{Q}_{b}$ & $\dot{W}_{\text {comp }} / \dot{Q}_{b}$ & $\dot{W}_{\text {aux,meth }} / \dot{Q}_{b}$ & $\eta_{b}$ & $\eta_{\text {oxy }}$ & $\eta_{\text {meth }}$ \\
{$[-]$} & {$[\%]$} & {$\left[\mathrm{kW}_{\mathrm{e}} / \mathrm{kW}_{\mathrm{t}}\right]$} & {$\left[\mathrm{kW}_{\mathrm{e}} / \mathrm{kW}_{\mathrm{t}}\right]$} & {$\left[\mathrm{kW}_{\mathrm{e}} / \mathrm{kW}_{\mathrm{t}}\right]$} & {$[\%]$} & {$[\%]$} & {$[\%]$} \\
\hline 0.00 & 0.0 & 0.060 & 0.049 & 0.000 & 91.6 & 83.4 & - \\
\hline 1.00 & 43.5 & 0.015 & 0.027 & 0.089 & 92.0 & 88.5 & 72.0 \\
\hline 1.33 & 57.9 & 0.000 & 0.020 & 0.119 & 92.1 & 90.3 & 72.0 \\
\hline 2.29 & 100.0 & 0.000 & 0.000 & 0.205 & 92.1 & 92.1 & 72.0 \\
\hline
\end{tabular}


The oxyfuel boiler operates at constant conditions of comburent excess ratio, temperatures and fuel composition and depends on the size ratio since the sources of oxygen will be different depending on the relative size of electrolyser and boiler. It presents values in the range of $91.6-92.1 \%$ for the simulated cases.

However, the energy efficiency of the oxyfuel subsystem increases rapidly while ASU is required since there is a strong reduction of its electrical consumption for larger $\xi_{\text {oxy }}$, Figure 7. Between $\xi_{A S U}$ and $\xi_{C O 2}$, the efficiency grows more slowly since only the $\mathrm{CO}_{2}$ compression stage diminishes its consumption in this range of operation. Above $\xi_{\mathrm{CO} 2}$, neither ASU nor compression consume power therefore the efficiency of the oxyfuel plant achieves its initial value and remains constant.

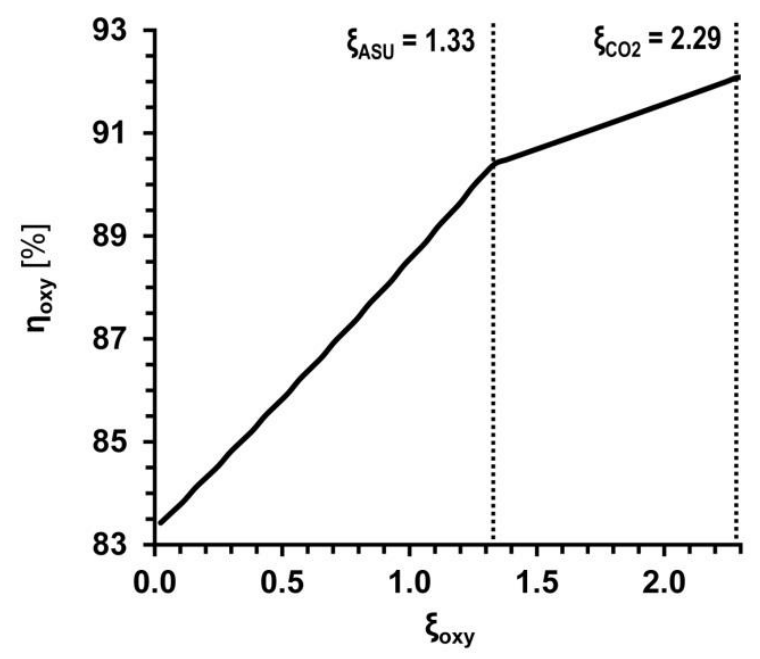

Figure 7. Oxyfuel plant efficiency vs. $\xi_{\text {oxy }}$

In the PtG subsystem, electrolysis efficiency may vary between $61.2 \%$ and $69.7 \%$ [15][16] depending on the selected technology, whilst methanation performance remains invariable with size ratio since it depends on its design. Hence, $\eta_{P t G}$ varies from $45.5 \%$ to $51.5 \%$, depending on electrolyser efficiency. 
Finally, the performance of the hybrid plant decreases with $\xi_{o x y}$ since the efficiency of the Power to Gas subsystem is lower than the efficiency of the oxyfuel boiler. Thus, the greater is the share of $\mathrm{PtG}$ in the hybrid system; the lower is the hybrid energy efficiency. Figure 8 illustrates this effect for a range of electrolyser consumption.

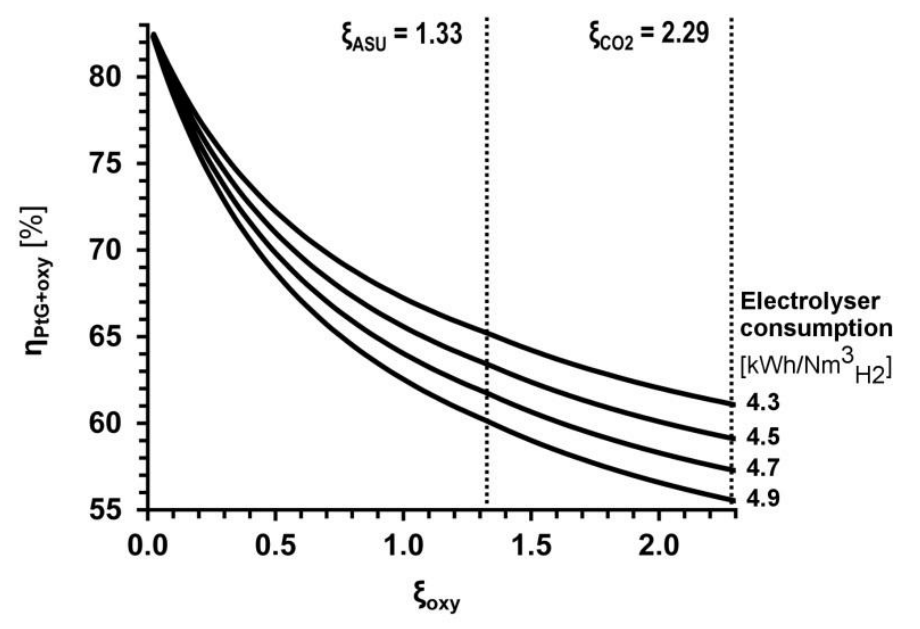

Figure 8. Overall efficiency of the hybrid system vs. $\xi_{\text {oxy }}$

The variations in energy efficiency introduced by the electrolysis performance becomes more significant at higher values of $\xi_{\text {oxy }}$, since its influence is larger, whilst at lower ratios it barely affects. At $\xi_{A S U}$ and $\xi_{C O 2}$, overall efficiency lies between $59.8-65.0 \%$, and $55.5-61.1 \%$, respectively.

The results obtained in this study may be applied to choose the most convenient sizes and operation ranges for large and small scale of the hybrid system. For small scale facilities $(0-100 \mathrm{~kW}), \mathrm{CO}_{2}$ emissions are a less relevant factor and size factors around 1.33 will be operative. Hence, the facility takes advantage of the suppression of ASU necessity without an excessive expenditure for a larger electrolyser. Large scale facilities will be more sensitive to the importance of $\mathrm{CO}_{2}$ emissions and, in the medium term, they might be regulated with the compulsory installation of carbon capture 
systems. Under this scenario, the operation range will lie around size factors of 2.29 since greater size ratios would generate a hydrogen excess and $\mathrm{CO}_{2}$ lack.

\section{4. $\mathrm{CO}_{2}$ emissions and $\mathrm{SNG}$ produced}

The carbon dioxide produced during oxyfuel combustion can be stored or used in methanation, depending on the size ratio of the system, $\xi_{o x y}$. When PtG is not included in the system, $\xi_{\text {oxy }}=0$, a flue gas flow of $367.2 \mathrm{~kg}_{\mathrm{CO} 2} / \mathrm{MW}_{\text {th }} \cdot \mathrm{h}$ is sent to compression. This amount linearly diminishes to zero as $\xi_{\text {oxy }}$ grows, until it reaches $\xi_{\mathrm{CO} 2}$ and produced $\mathrm{CO}_{2}$ emissions are completely conducted into the methanators. In the intermediate operation point $\xi_{A S U}$, only $153.9 \mathrm{~kg}_{\mathrm{CO} 2} / \mathrm{MW}_{\text {th }} \cdot \mathrm{h}$ have to be compressed and transported for storage since the rest is processed in methanation stage.

Similarly, specific synthetic natural gas generated increases linearly with $\xi_{\text {oxy }}$. For $\xi_{A S U}, 78.5 \mathrm{~kg}_{\mathrm{SNG}} / \mathrm{MW}_{\text {th }} \cdot \mathrm{h}$ are produced whilst the maximum achievable value corresponds to the operational point $\xi_{\mathrm{CO} 2}, 135.2 \mathrm{~kg}_{\mathrm{SNG}} / \mathrm{MW}_{\mathrm{th}} \cdot \mathrm{h}$. The lower heating value of the SNG produced in the simulated system is $47.7 \mathrm{MJ} / \mathrm{kg}_{\mathrm{SNG}}$, therefore, the maximum energy that can be stored consuming the carbon dioxide from the oxyfuel combustion is $1.8 \mathrm{MWh}$ per thermal MWh produced in the boiler.

\section{Conclusions}

The potential storage of energy by means of $\mathrm{PtG}$ hybridization, through the combination of a methanation plant and an oxycombustion coal boiler, has been proposed and analysed. This hybridization takes advantage of the $\mathrm{O}_{2}$ produced in the electrolyser and overcome the penalty of $\mathrm{CO}_{2}$ capture required for the Sabatier reaction. It is concluded that represents an interesting option for energy supply and energy storage in a medium

term. The parameter used to characterize the system is the size ratio, $\xi_{\text {oxy }}$, which 
represents the energy contained in the hydrogen produced in the electrolyser divided by the net thermal power produced by the oxyfuel boiler. The results obtained from the Aspen Plus ${ }^{\circledR}$ simulation of both subsystems have allowed defining different strategic ranges of operation for a PtG-oxycombustion hybridized plant. Thus, when $\xi_{\text {oxy }}=1.33$, the ASU becomes unnecessary and $\mathrm{CO}_{2}$ consumed in methanation reaches the $57.9 \%$ of total flue gas from the boiler. If $\xi_{o x y}$ is increased up to 2.29 , then flue gas is completely reused and converted to SNG. The continued augmentation of $\xi_{\text {oxy }}$ from 0 to 2.29 leads to an increment in oxyfuel combustion plant efficiency, due to the suppression of $\mathrm{ASU}$ and $\mathrm{CO}_{2}$ compression stage consumptions. However, the efficiency of the hybrid system decays with $\xi_{\text {oxy }}$ since PtG presents a lower efficiency than oxycombustion process and the increment of PtG share in the system acts as a penalty. The evaluation of the annual plant performance (considering $7000 \mathrm{hr} / \mathrm{yr}$ operation) reveals that $1493 \mathrm{t}_{\mathrm{CO} 2} / \mathrm{MW}_{\mathrm{th}}$ and $2570 \mathrm{t}_{\mathrm{CO} 2} / \mathrm{MW}_{\text {th }}$ could be avoided by the system operated at $\xi_{A S U}$ and $\xi_{C O 2}$, respectively. The hybridization could also save those $\mathrm{CO}_{2}$ emissions associated to the ASU electric consumption which corresponds to 422.8 MWh per net MWth of the boiler. Furthermore, through the processing of this carbon dioxide flow, $549.5 \mathrm{t}_{\mathrm{SNG}} / \mathrm{MW}_{\text {th }}$ and $946.4 \mathrm{t}_{\mathrm{SNG}} / \mathrm{MW}_{\text {th }}$ would be yearly generated at $\xi_{A S U}$ and $\xi_{\mathrm{CO} 2}$.

\section{Acknowledgements}

The authors would like to acknowledge funding from Fundación Iberdrola through the program “Ayudas a la Investigación en Energía y Medioambiente”.

\section{Nomenclature}

\section{Variables}




$\begin{array}{ll}L H V & \text { Lower heating value }[\mathrm{kJ} / \mathrm{kg}] \\ M & \text { Moisture } \\ \dot{n} & \text { Molar flow }[\mathrm{kmol} / \mathrm{s}] \\ \dot{Q} & \text { Thermal power }[\mathrm{kWt}] \\ R & \text { Recirculation percentage in methanation reactors }[\%] \\ \dot{W} & \text { Electric power [kWe] } \\ y & \text { Molar fraction }[-] \\ Z & \text { Ashes } \\ \eta & \text { Efficiency }[\%] \\ \xi_{\text {oxy }} & \text { Ratio between electrolyser power and boiler net output }[\mathrm{kWe} / \mathrm{kWt}] \\ \phi_{F G M} & \text { Percentage of flue gas directed to methanation }[\%]\end{array}$

\section{Subscripts}

$\begin{array}{ll}\text { air } & \text { Input air to ASU } \\ \text { ASU } & \text { Air separation unit } \\ \text { aux } & \text { Auxiliary consumption } \\ b & \text { Boiler } \\ \mathrm{CO}_{2} & \text { Carbon dioxide } \\ \text { comp } & \mathrm{CO}_{2} \text { compression train } \\ \text { ele } & \text { Electrolyser } \\ f & \text { Fuel } \\ \mathrm{FG} & \text { Flue gas } \\ \mathrm{H}_{2} & \text { Hydrogen } \\ \text { Loss } & \text { Losses in condensation phase at point }(2 \mathrm{c}) \text { in Figure } 4 \\ \text { meth } & \text { Methanation } \\ \mathrm{O}_{2} & \text { Oxygen } \\ \text { oxy } & \text { Oxycombustion plant } \\ P t G & \text { Power to Gas } \\ P t G+\text { oxy } & \text { Power to Gas-Oxycombustion hybrid system } \\ r e f & \text { Reference state } \\ \text { th } & \text { Thermal energy } \\ \text { water } & \text { Input water to electrolyser }\end{array}$

\section{References}

[1] Chatzivasileiadi A, Ampatzi E, Knight I. Characteristics of electrical energy storage technologies and their applications in buildings. Renew Sustain Energy Rev 2013;25:814-30. doi:10.1016/j.rser.2013.05.023.

[2] International Energy Agency. Technology Roadmap: Energy Storage. 2013. doi:10.1007/SpringerReference_7300.

[3] Vandewalle J, Bruninx K, D'haeseleer W. Effects of large-scale power to gas conversion on the power, gas and carbon sectors and their interactions. Energy Convers Manag 2015;94:28-39. doi:10.1016/j.enconman.2015.01.038. 
[4] Gahleitner G. Hydrogen from renewable electricity: An international review of power-to-gas pilot plants for stationary applications. Int J Hydrogen Energy 2013;38:2039-61. doi:10.1016/j.ijhydene.2012.12.010.

[5] Sterner M. Bioenergy and renewable power methane in integrated $100 \%$ renewable energy systems. University of Kassel, 2009.

[6] Gao J, Wang Y, Ping Y, Hu D, Xu G, Gu F, et al. A thermodynamic analysis of methanation reactions of carbon oxides for the production of synthetic natural gas. RSC Adv 2012;2:2358. doi:10.1039/c2ra00632d.

[7] Iskov H, Rasmussen N. Global screening of projects and technologies for Powerto-Gas and Bio-SNG. 2013.

[8] Kirchmayr M. Power-to-Gas: Modellierung der Energieverwertungspfade und Einflussnahme einer veränderten Strommarktsituation. Diplomica Verlag GmbH; 2014.

[9] Denmark turns excess wind power into gas via Hydrogenics tech. Fuel Cells Bull 2014;2014:8-9. doi:10.1016/S1464-2859(14)70082-3.

[10] Szwaja S, Kovacs VB, Bereczky A, Penninger A. Sewage sludge producer gas enriched with methane as a fuel to a spark ignited engine. Fuel Process Technol 2013;110:160-6. doi:10.1016/j.fuproc.2012.12.008.

[11] ACER / CEE. Annual Report on the Results of Monitoring the Internal Electricity and Natural Gas Markets in 2012. 2013. doi:10.2851/14037.

[12] Buchholz OS, van der Ham AGJ, Veneman R, Brilman DWF, Kersten SR a. Power-to-Gas: Storing Surplus Electrical Energy. A Design Study. Energy Procedia 2014;63:7993-8009. doi:10.1016/j.egypro.2014.11.836.

[13] Eisentraut A, Brown A. Heating without global warming. Market developments and policy considerations for renewable heat. 2014.

[14] Hu Y, Li X, Li H, Yan J. Peak and off-peak operations of the air separation unit in oxy-coal combustion power generation systems. Appl Energy 2013;112:74754. doi:10.1016/j.apenergy.2012.12.001.

[15] Tijani AS, Yusup NAB, Rahim a. HA. Mathematical Modelling and Simulation Analysis of Advanced Alkaline Electrolyzer System for Hydrogen Production. Procedia Technol 2014;15:799-807. doi:10.1016/j.protcy.2014.09.053.

[16] Dieguez P, Ursua a, Sanchis P, Sopena C, Guelbenzu E, Gandia L. Thermal performance of a commercial alkaline water electrolyzer: Experimental study and mathematical modeling. Int J Hydrogen Energy 2008;33:7338-54. doi:10.1016/j.ijhydene.2008.09.051. 
[17] Kopyscinski J, Schildhauer TJ, Biollaz SM a. Production of synthetic natural gas (SNG) from coal and dry biomass - A technology review from 1950 to 2009. Fuel 2010;89:1763-83. doi:10.1016/j.fuel.2010.01.027.

[18] Sudiro M, Bertucco a. Synthetic Natural Gas (SNG) from coal and biomass: a survey of existing process technologies, open issues and perspectives. Nat Gas 2010:105-27. doi:10.5772/9835.

[19] BOE-A-2013-185. Resolución de 21 de diciembre de 2012, de la Dirección General de Política Energética y Minas, por la que se modifica el protocolo de detalle PD-01. Ministerio de Industria, Energía y Turismo; 2013.

[20] Agersborg J, Lingehed E. Integration of Power-to-Gas in Gasendal and GoBiGas. Chalmers University of Technology, 2013.

[21] Nguyen TTM, Wissing L, Skjøth-Rasmussen MS. High temperature methanation: Catalyst considerations. Catal Today 2013;215:233-8. doi:10.1016/j.cattod.2013.03.035.

[22] Rostrup-Nielsen JR, Pedersen K, Sehested J. High temperature methanation. Sintering and structure sensitivity. Appl Catal A Gen 2007;330:134-8. doi:10.1016/j.apcata.2007.07.015.

[23] Heyne S, Seemann MC, Harvey S. Integration study for alternative methanation technologies for the production of synthetic natural gas from gasified biomass. Chem Eng Trans 2010;21:409-14. doi:10.3303/CET1021069.

[24] Li S, Ji X, Zhang X, Gao L, Jin H. Coal to SNG: Technical progress, modeling and system optimization through exergy analysis. Appl Energy 2014;136:98109. doi:10.1016/j.apenergy.2014.09.006. 


\section{List of figures}

Figure 1: Scheme of the hybrid power system

Figure 2: Oxyfuel combustion plant model

Figure 3: Methanation plant model

Figure 4: Specific deposition of solid carbon vs. condensation temperature and M1 recirculation

Figure 5: Methane molar fraction vs. recirculation

Figure 6: Specific consumptions and percentage of consumed flue gas vs. $\boldsymbol{\xi}_{\text {oxy }}$

Figure 7: Oxyfuel plant efficiency vs. $\xi_{\text {oxy }}$

Figure 8: Overall efficiency of the hybrid system vs. $\boldsymbol{\xi}_{\text {oxy }}$

\section{List of tables}

Table 1: Ultimate analysis of coal for oxycombustion [\% w.b.]

Table 2: Main parameters and efficiencies of the hybrid system. 